\title{
Determination of Antiemetic, Antimicrobial, Anti-Radical and Cytotoxic Activity of Methanolic Extracts of Centella asiatica
}

\author{
Md. Shohel Hossain ${ }^{1}$, Fahmida Abdullah Tuly ${ }^{1}$, Sharmin Akter ${ }^{1}$, Md Saiful Islam Arman ${ }^{1}$, \\ Md. Abdul Aziz ${ }^{1}$, Md. Ekhtear Mahmud ${ }^{2}$, Palash Das ${ }^{3}$, Mohammad Hasem Babu ${ }^{3}$, \\ Md. Monirul Islam ${ }^{4}$ *
}

${ }^{1}$ Department of Pharmacy, Manarat International University, Dhaka, Bangladesh

${ }^{2}$ Department of Pharmacy, University of Asia Pacific, Dhaka, Bangladesh

${ }^{3}$ Department of Pharmacy, Atish Dipankar University of Science and Technology, Dhaka, Bangladesh

${ }^{4}$ Department of Pharmacy, State University of Bangladesh, Dhaka, Bangladesh

Email address:

amin.pharma07@gmail.com(Md. M. Islam)

${ }^{*}$ Corresponding author

\section{Tocitethisarticle:}

Md. Shohel Hossain, Fahmida Abdullah Tuly, Sharmin Akter, Md Saiful Islam Arman, Md. Abdul Aziz, Md. Ekhtear Mahmud, Palash Das, Mohammad Hasem Babu, Md. Monirul Islam. Determination of Antiemetic, Antimicrobial, Anti-Radical and Cytotoxic Activity of Methanolic Extracts of Centella asiatica. Plant. Vol. 6, No. 1, 2018, pp. 1-7. doi: 10.11648/j.plant.20180601.11

Received: March 5, 2018; Accepted: March 24, 2018; Published: April 13, 2018

\begin{abstract}
This study was conducted to investigate the antiemetic, antimicrobial, antioxidant and cytotoxic activity of methanolic extracts of Centella asiatica. The antiemetic assay was carried out by using chick emetic model with minor modifications by calculating the mean decrease in the number of retching. The antimicrobial activity of the crude extract was performed by Disc Diffusion method. The anti-radical activity was determined by the 2,2-diphenyl-2-picrylhydrazyl hydrate (DPPH) method. Brine shrimp lethality bioassay is done to determine cytotoxic activity. The anti-emetic activity of Centella asiatica leaves on young chicks revealed that these extracts have a less anti-emetic effect. The group of chicks treated with Chlorpromazine was found to have 38.4 retches as compared to the 60.4 retches of the control group, thus Chlorpromazine reduced the retches by $36.96 \%$. The chickens treated with leaves extracts inhibited the retches up to $15.67 \%$. The manimum antimicrobial effect was found in this methanol crude extract. The extract did not appear potent in terms of both zones of inhibition and spectrum of activity. In anti-radical activity test, the extract showed moderate free radical scavenging activity with IC50 value $241.71 \mu \mathrm{g} / \mathrm{ml}$. while compared to that of the reference standard ascorbic acid. Moreover, the methanolic crude extracts also possess moderate cytotoxic principles potential (LC50 value of $39.06 \mu \mathrm{g} / \mathrm{ml}$ ) comparing with that of standard vincristine $(0.839 \mu \mathrm{g} / \mathrm{ml})$.
\end{abstract}

Keywords: Antiemetic, Antimicrobial, Antioxidant, Cytotoxicity, Centella asiatica

\section{Introduction}

A large amount of diverse bioactive compounds are produced from plant sources that provide not only basic nutrition but also health benefits. Various studies show that diet well provided with vegetables and fruits are advantageous for health [1]. Epidemiological evidence suggests that vitamins A, C, E, and phenolic compounds (flavonoids, tannins, and lignins) perform vital roles to delay aging, reduce inflammation, and prevent certain type of cancers [2].The outstanding revolution of modern medicine actually comes from the natural sources and the medicinal plants play an important role from the beginning of this track. Estimation shows that about $80 \%$ of world's population use plants as medicine [3]. The medicinal plants are rich in secondary metabolites and essential oils of 
therapeutic importance. Only 150-200 plants are used in western medicine where about 10,000 to 15,000 plants are listed for medicinal significance worldwide [4]. Demand for the medicinal plant is increasing in both developing and developed countries due to growing recognition of natural products, being non-narcotic, having no side-effects, easily available at affordable prices and sometimes the only source of health care available to the poor.

Antiemetic agents work against emesis that is induced by side effects of various drugs usually general anesthetics, opioid analgesics, chemotherapy for cancer and motion sickness [5]. Synthetic antiemetic drugs also show side effects after long-term use. Thus natural products manufacturing has remarkably become a timely demand [6] Antimicrobial susceptibility testing is applied for drug discovery and investigation of potential antimicrobial agents [7]. Microbial resistance is increasing day by day generating uncertainty about the future use of antimicrobial drugs. Plants extracts and Phytochemicals with known antimicrobial properties can be significantly used for therapeutic treatments [8].

Oxygen-derived radicals or ROS are generated constantly as part of normal aerobic life which is responsible for different diseases. Thus the study of free radicals has been considered a great deal of interest in recent years [9]. ROS are able to damage vital molecules like DNA, lipids, carbohydrates, proteins etc as they are highly reactive and unstable [10]. Studies show that high level of free radicals results in various fatal diseases like cancer and respiratory disorder [11], cardiovascular disease [12], diabetes and neurodegenerative disease [13], arthritis [14], hypertension and preeclampsia [15]. Antioxidants reduce the damaging ability of free radicals by donating an electron to a rampaging free radical and neutralizing it [16]. Phytochemicals that protect against free radical damage, accumulate in fruits and vegetables in high concentration. They act as natural antioxidants that limit and lessen the oxidative damage caused by reactive oxygen species (ROS) $[17,18]$.

Centella asiatica (C. asiatica) (Apiaceae family) also known as Hydrocotyle asiatica, Asiatic pennywort or Indian pennywort is herbaceous, self-fertile, can grow in semi-shade or no shade, frost-tender evergreen perennial plants with an aromatic odor. It is indigenous to the Indian subcontinent, Southeast Asia, and wetland regions of the Southeastern US. Now it is widely cultivated throughout the temperate and tropical regions of the world. It is also a very popular medicinal and economic plant in Indonesia, In Vietnam, Thailand, China, India and Bangladesh people use $C$. asiatica as salad ingredients and healthy drinks [19]. It is well known for its medicinal value in several traditional systems of medicine such as Ayurvedic medicine, Western Herbal Medicine, traditional African medicine, traditional Chinese medicine and in western orthodox medicine. In Ayurveda, It is used for the treatment of urethritis [20], wound healing [21, 22], for revitalizing the nerves and brain cells [23], ulcers [24], leprosy, skin diseases, asthma, body aches, bronchitis, elephantiasis, eczemas, anxiety, cataract, eye troubles, diarrhoea among children [25]. Besides, it promotes fibroblast proliferation and collagen synthesis [26].

This study was conducted to investigate the antiemetic, antimicrobial, antioxidant and cytotoxic activity of methanolic extracts of C. asiatica.

\section{Materials and Methods}

\subsection{Chemicals}

All of the chemicals used in this study were of analytical grade. Copper sulfate was purchased from Scharlau Chem-ie S.A. Barcelona, Spain. Metoclopramide hydrochloride was collected from Eskayef Bangladesh Ltd. Dimethyl sulfoxide (DMSO), Polyoxyethylene sorbitan monooleate (Tween 80) and methanol was purchased from Merck, Darmstadt, Germany.

\subsection{Collection and Proper Identification of Plants Sample}

The plant was collected from Lakshmipur District, Bangladesh and was identified by Botany Department, Noakhali Government University College, Noakhali.

\subsection{Drying and Grinding of Plant Materials}

The collected plant parts (leaves) were separated from undesirable materials and washed with water to eradicate adhering dirt. They were sun-dried for a week and grind into a coarse powder with the help of a suitable grinder. The grinded powder was stored in an airtight container and kept in a cool, dark and dry place until analysis commenced.

\subsection{Extraction of Plant Materials}

The Powdered material having a weight of 225 gm ware taken in a clean, flat-bottomed colored glass container and drenched in $1200 \mathrm{ml}$ of methanol at $25^{\circ} \mathrm{C}$. To resist the entrance of air the container with its contents was closed properly and preserved for 7 days accompanying occasional shaking and stirring to get better extraction. The whole mixture then underwent to a coarse filtration by a piece of clean, white cotton material. Then it was filtered through a cotton plug. The filtrate (methanol extract) obtained was evaporated under the ceiling fan and in a water- bath until dried. It rendered a gummy concentrate of greenish black color. The gummy concentrate was designated as a crude extract of methanol.

\subsection{In Vivo Antiemetic Activity}

The antiemetic assay was carried out by using chick emetic model [27] with minor modifications by calculating the mean decrease in the number of retching. Young male chicks, 2- 4 days of age, weighing from 30-32 gm were obtained from a local poultry store. After $24 \mathrm{hrs}$ fasting, the antiemetic activity was evaluated. The chicks were divided into three groups of five chicks each and each chick was kept in a large beaker at $25^{\circ} \mathrm{C}$ for 10 minutes. The extracts of $C$. 
asiatica leaves dissolved in $0.9 \%$ saline containing $5 \%$ DMSO and $1 \%$ Tween 80 and administered at a dose of 150 $\mathrm{mg} / \mathrm{kg}$ and $10 \mathrm{ml} / \mathrm{kg}$ of control orally to the test animal on the basis of their body weights. Control groups received only saline solution $(0.9 \% \mathrm{NaCl}$ solution). After 10 minutes copper sulfate was administered orally at $50 \mathrm{mg} / \mathrm{kg}$, then the number of retching was observed during next ten minutes. Chlorpromazine was used as a standard drug (150 $\mathrm{mg} / \mathrm{kg}$.b.w).

The antiemetic effect was assessed as the decrease in thenumber of retches in the treated group in contrast to the control. The inhibition (\%) was calculated as follows:

$$
\text { Inhibition }(\%)=[(\mathrm{A}-\mathrm{B}) / \mathrm{A}] \times 100
$$

Where A is the frequency of retching of control group and $\mathrm{B}$ is the frequency of retching of the treated group.

\subsection{Antimicrobial Screening}

The antimicrobial assay of the crude extract of $C$. asiatica was carried out by Disc Diffusion method. The bacterial and fungal strains used in the experiment were collected as pure cultures from the Institute of Food and Nutrition, University of Dhaka, Bangladesh. Staphylococcus aureus was taken as a gram-positive organism and Escherichia coli, Pseudomonas aeruginosa, Entero bacterand Vibrio cholera were taken as gramnegative organisms. Nutrient agar medium (DIFCO) was used in the present study for testing the sensitivity of the organisms to the test materials and to prepare fresh cultures.

\subsection{Preparation of the Medium}

To prepare the required volume of this medium, the calculated amount of each of the constituents was taken in a conical flask and distilled water was added to it to make the required volume. The contents were heated in a water bath to make a clear solution. The $\mathrm{pH}\left(\right.$ at $25^{\circ} \mathrm{C}$ ) was adjusted at 7.27.6 using $\mathrm{NaOH}$ or $\mathrm{HCl} .10 \mathrm{ml}$ and $5 \mathrm{ml}$ of the medium was then transferred in screw cap test tubes to prepare plates and slants respectively. The test tubes were then capped and sterilized by autoclaving at 15 -lbspressure at $121^{\circ} \mathrm{C}$ for 20 minutes. The slants were used for making the fresh culture of bacteria and fungi that were in turn used for sensitivity study.

In an aseptic condition, the test organisms were transferred from the pure cultures to the agar slants. The inoculated strains were then incubated for 24 hours at $37^{0} \mathrm{C}$ for their optimum growth.

The test organisms were then transferred from the subculture to the test tubes containing about $10 \mathrm{ml}$ of melted and sterilized agar medium. The test tubes were shaken and the bacterial and fungal suspension was immediately transferred to the sterilized petridishes. Three types of discs were used for antimicrobial screening. Standard Discs were used as positive control to ensure the activity of standard antibiotic against the test organisms. In this investigation, Ciprofloxacin $5 \mathrm{mg}$ standard disc was used as the reference.
Blank Discs were used as negative controls which ensure that the residual solvents and the filter paper were not active themselves.

Methanolic extract of $C$. asiatica was dissolved in methanol to obtain the desired concentrations $(400(\mu \mathrm{g} / \mathrm{disc})$ in an aseptic condition. Sterilized metrical (BBL, Cocksville, USA) filter paper discs were taken in a blank petridish under the laminar hood. Then discs were soaked with solutions of test samples and dried.

The sample discs, the standard antibiotic discs and the control discs were placed gently on the previously marked zones in the agar plates pre-inoculated with test bacteria and fungi. The plates were then kept in a refrigerator at $4{ }^{\circ} \mathrm{C}$ for about 24 hours upside down to allow sufficient diffusion of the materials from the discs to the surrounding agar medium. The plates were then inverted and kept in an incubator at $37^{\circ} \mathrm{C}$ for 24 hours.

After incubation, the antimicrobial potency of the test materials was determined by measuring the diameter of the zones of inhibition in millimeter with a transparent scale.In order to avoid any type of cross-contamination by the test organisms, the antimicrobial screening was done in Laminar Hood and all types of precautions were highly maintained. Petridishes and other glassware, Micropipette tips, cotton, forceps, blank discs etc. were also sterilized.

\subsection{The Anti-Radical Activity}

The free radical scavenging activity (antioxidant potential) was determined by the 2,2-diphenyl-2-picrylhydrazyl hydrate (DPPH) method [28]. DPPH is a stable free radical having delocalized spare electron over the molecule which produces a deep violet color. When a substance having the ability to donate a proton is mixed with a DPPH solution, the violet color disappears indicating the reduced form of DPPH [29]. $0.3 \mathrm{mg} \mathrm{DPPH}(0.004 \% \mathrm{w} / \mathrm{v})$ is weighted accurately and dissolved in $15 \mathrm{ml}$ methanol to make the concentration 20 $\mu \mathrm{g} / \mathrm{ml} .100 \mathrm{mg}$ of dried sample extract was dissolved in 10 $\mathrm{ml}$ of methanol for the concentration of sample solution 10 $\mu \mathrm{g} / \mathrm{ml} .21$ test tubes were taken and each of this labeled for $5 \mathrm{ml}$, in which 10 test tubes for different conc. of thesample solution, 10 test tubes for different conc. of standard solution and 1 test tubes for blank which was filled with $3 \mathrm{ml} \mathrm{DPPH}$ solution and $2 \mathrm{ml}$ of methanol. In each test tube (Except blank test tube) $3 \mathrm{ml}$ of DPPH solution $(20 \mu \mathrm{g} / \mathrm{ml})$ was taken and then mixed at different concentration $(500 \mu \mathrm{g} / \mathrm{ml}, 250 \mu \mathrm{g} / \mathrm{ml}$, $125 \mu \mathrm{g} / \mathrm{ml}, 62.5 \mu \mathrm{g} / \mathrm{ml}, 31.25 \mu \mathrm{g} / \mathrm{ml}, 16.625 \mu \mathrm{g} / \mathrm{ml}, 7.813$ $\mu \mathrm{g} / \mathrm{ml}, 3.906 \mu \mathrm{g} / \mathrm{ml}, 1.953 \mu \mathrm{g} / \mathrm{ml}$ and $0.997 \mu \mathrm{g} / \mathrm{ml}$ ) of $2 \mathrm{ml}$ sample solution. After $30 \mathrm{~min}$ reaction period at room temperature in dark place, the absorbance was taken at 517 $\mathrm{nm}$ against methanol as blank by UV spectrophotometer. The Control sample was prepared by using the same conc. of ascorbic acid instead of sample solution (plant extract).The absorbance was recorded and percentage scavenging $\left(\mathrm{IC}_{50} \%\right)$ was determined using the following equation and was compared with ascorbic acid which was used as a standard. 


$$
\left(\mathrm{IC}_{50} \%\right)=(1-\text { Absorbance of test sample / Absorbance of control }) X 100
$$

Where Absorbance of the control means blank absorbance (containing all reagents except the test material).

Extract concentration providing $50 \%$ inhibition $\left(I C_{50}\right)$ was calculated from the graph plotted inhibition percentage against extract concentration.

\subsection{Cytotoxic Activity}

Brine shrimp lethality bioassay is a simple, rapid, reliable, inexpensive and convenient cytotoxicity test of bioactive compounds. It is established on the killing ability of a simple zoological organism Artemia salina (brine shrimp eggs) used to determine the cytotoxic activity [30].The brine shrimp eggs collected from pet shops was used as the test organism. Two days (48 hours) were allowed to hatch the shrimp and to be matured as naupliiin artificial seawater $(3.8 \% \mathrm{NaCl}$ solution) $[31,32]$. Constant oxygen supply was provided throughout the hatching time. $4 \mathrm{mg}$ of the sample was dissolved in $200 \mu \mathrm{l}$ of DMSO and diluted as 400, 200, 100, 50, 25, 12.5, 6.25, 3.125, $1.5625,0.78125 \mu \mathrm{g} / \mathrm{ml}$ by serial dilution method in each vial containing $5 \mathrm{ml}$ of saline water $(3.8 \% \mathrm{NaCl}$ solution). $100 \mu \mathrm{l}$ DMSO diluted to $5 \mathrm{ml}$ of simulated seawater was used as a negative control. Standard vincristine sulfate was used as positive control. Ten living nauplii were added to all experimental and control vials with the help of Pasteur pipette. After 24 hours keeping undisturbed, each vial was inspected to count lived nauplii using a magnifying glass. Obtained data were used to calculate the percent mortality for each concentration by the following equation

$\%$ mortality $=($ no. of dead nauplii/ initial no. of live nauplii $) \times 100$.

Where,

The Initial number of live nauplii is 10 . The median lethal concentration $\left(\mathrm{LC}_{50}\right)$ was determined from the graph plotting $\log$ of concentration versus percent mortality.

\subsection{Statistical Analysis}

All numerical data are expressed as the mean \pm SEM (standard error of the mean) and Statistical analysis was carried out using Student'st-test and differences between means were considered to be significant when $\mathrm{p}<0.05$.

\section{Result}

\subsection{In Vivo Antiemetic Activity}

Number of retches recorded for crude methanolic extracts of $C$. asiatica leaves and standard drug is given in table below -

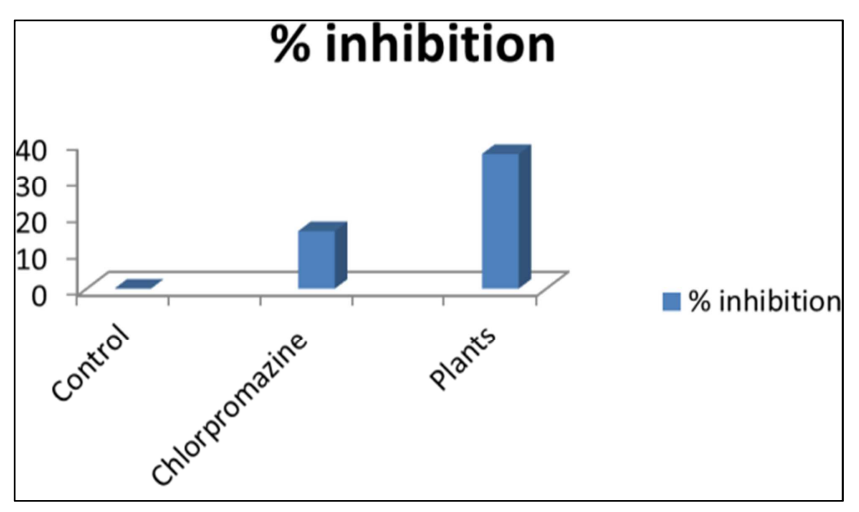

Figure 1. \% of inhibition of retches of white leghorn for leave extracts.

Table 1. \% of inhibition of Retches for C.asiatica Extract.

\begin{tabular}{lll}
\hline Drug/Dose & $\begin{array}{l}\text { No. of retches } \\
\text { (Mean } \pm \text { SEM) }\end{array}$ & \% inhibition \\
\hline Control $(10 \mathrm{ml} / \mathrm{kg})$ & $60.4 \pm 13.93$ & 0.00 \\
Chlorpromazine $(150 \mathrm{mg} / \mathrm{kg})$ & $38.4 \pm 10.19$ & $36.96 \%$ \\
\hline
\end{tabular}

\begin{tabular}{lll}
\hline Drug/Dose & $\begin{array}{l}\text { No. of retches } \\
(\text { Mean } \pm \text { SEM) }\end{array}$ & \% inhibition \\
\hline Centella asiatica leaves $(150 \mathrm{mg} / \mathrm{kg})$ & $49.2 \pm 4.22$ & $15.67 \%$ \\
\hline
\end{tabular}

\subsection{Antimicrobial Screening}

The methanolic crude extract didn't inhibit the growth of Staphylococcus aureus, Escherichia coli, Pseudomonas aeruginosa, Vibrio cholera, Enterobacter having zone size 4 $\mathrm{mm}, 1 \mathrm{~mm}, 2 \mathrm{~mm}, 5 \mathrm{~mm}$ and $3 \mathrm{~mm}$ respectively.

Out of all the samples, the methanolic crude extract did not appear potent in terms of both zones of inhibition and spectrum of activity.

Table 2. Antimicrobial activity of test samples of C. asiatica.

\begin{tabular}{llc}
\hline \multirow{2}{*}{ Test microorganisms } & \multicolumn{2}{c}{ Diameter of zone of inhibition (mm) \pm SEM } \\
\cline { 2 - 3 } & MCE & Ciprofloxacin \\
\hline Gram-positiveBacteria & & $16 \pm 0.37$ \\
$\begin{array}{l}\text { Staphylococcusaureus } \\
\text { Gram-negativeBacteria }\end{array}$ & $4 \pm 0.33$ & \\
Escherichiacoli & $1 \pm 0.02$ & $31 \pm 1.15$ \\
Pseudomonasaeruginosa & $2 \pm 0.57$ & $36 \pm 1.32$ \\
Vibrio Cholera & $5 \pm 0.88$ & $11 \pm 1.45$ \\
Enterobacter & $3 \pm 0.34$ & $30 \pm 1.84$ \\
\hline
\end{tabular}

[MCE: Methanolic crude extract of the leaves $(400 \mu \mathrm{g} / \mathrm{disc})]$

\subsection{The Anti-Radical Activity}

The methanol extract of $C$. asiatica was tested for Free radical scavenging activity. The absorbance of different concentration of methanol extract of plant seeds of $C$. asiatica is shown below.

Table 3. $I C_{50}$ value of methanol soluble fraction of $C$. asiatica and ascorbic acid.

\begin{tabular}{lll}
\hline S.N. & Sample & IC $_{\mathbf{5 0}}(\boldsymbol{\mu g} / \mathbf{m l})$ \\
\hline 1. & Methanol soluble fraction & 241.71 \\
2. & Ascorbicacid & 27.23 \\
\hline
\end{tabular}




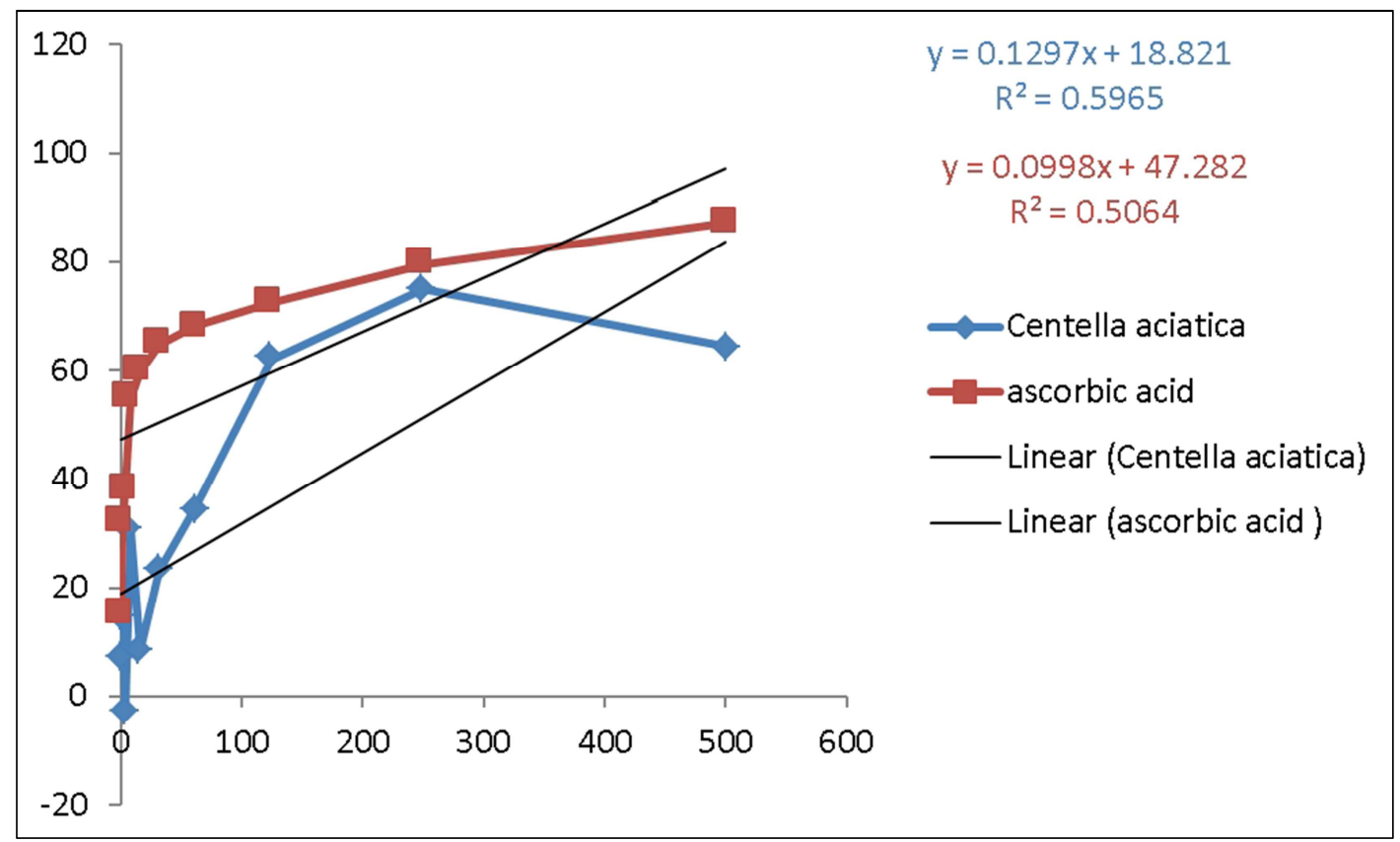

Figure 2. $I C_{50}$ value for extract and ascorbic acid standard using DPPH.

\subsection{Brine Shrimp Lethality Bioassay}

Bioactive compounds are almost always toxic at a higher dose. Thus, in vivo lethality in a simple zoological organism can be used as a convenient informant for screening and fractionation in the discovery of new bioactive natural products. In the present bioactivity study, the summary of the result was given below.

Table 4. Results of the test sample of Centella asiatica.

\begin{tabular}{llll}
\hline Sample & $\mathbf{L C}_{\mathbf{5 0}}(\boldsymbol{\mu g} / \mathbf{m l})$ & Regression Equation & $\mathbf{R}^{\mathbf{2}}$ \\
\hline Vincristine Sulphate (Positive control) & 0.839 & $\mathrm{y}=34.02 \mathrm{x}+52.58$ & 0.952 \\
Methanol Extract & 39.06 & $\mathrm{y}=40.668 \mathrm{x}-14.731$ & 0.906 \\
\hline
\end{tabular}

Table 5. Effect of Methanolic Extract of Centella asiatica and Vincristine Sulphate on Brine Shrimp Nauplii.

\begin{tabular}{|c|c|c|c|c|c|c|c|}
\hline \multicolumn{4}{|l|}{ MethanolExtract } & \multicolumn{4}{|c|}{ Vincristine Sulphate } \\
\hline Conc $(C)(\mu \mathrm{g} / \mathrm{ml})$ & $\log C$ & $\%$ Mortality & $\begin{array}{l}\mathrm{LC}_{50}(\mu \mathrm{g} / \mathrm{ml}) \text { Based on } \\
\log C\end{array}$ & $\begin{array}{l}\text { Conc } \\
(\mathrm{C})(\mu \mathrm{g} / \mathrm{ml})\end{array}$ & $\log C$ & $\%$ Mortality & $\operatorname{LC}_{50}(\mu \mathrm{g} / \mathrm{ml})$ Based on Log C \\
\hline 400 & 2.602059991 & 100 & & 40 & 1.602059991 & 100 & \\
\hline 200 & 2.301029996 & 90 & & 20 & 1.301029996 & 90 & \\
\hline 100 & 2.00000000 & 70 & & 10 & 1.00000000 & 90 & \\
\hline 50 & 1.698970004 & 50 & & 5 & 0.698970004 & 80 & \\
\hline 25 & 1.397940009 & 30 & 3006 & 2.5 & 0.397940009 & 70 & 0820 \\
\hline 12.5 & 1.096910013 & 10 & 39.00 & 1.25 & 0.096910013 & 70 & 0.839 \\
\hline 6.25 & 0.795880017 & 10 & & .625 & -0.20411998 & 50 & \\
\hline 3.125 & 0.494850022 & 0 & & .3125 & -0.50514997 & 30 & \\
\hline 1.5625 & 0.193820026 & 0 & & .15625 & -0.80617997 & 20 & \\
\hline .78125 & -0.10720997 & 0 & & .078125 & -1.10720997 & 10 & \\
\hline
\end{tabular}

\section{Discussion}

The anti-emetic activity of $C$. asiatica leaves on young chicks revealed that these extracts have a less anti-emetic effect. After administration of a dose of $150 \mathrm{mg} / \mathrm{kg}$ Chlorpromazine and the extracts of leaves, the numbers of retches were reduced. The group of chicks treated with Chlorpromazine was found to have 38.4 retches as compared to the 60.4 retches of the control group, thus Chlorpromazine reduced the retches by $36.96 \%$. The chickens treated with leaves extracts inhibited the retches up to $15.67 \%$. Therefore, the extract of leaves inhibited emesis to an extent not greater than Chlorpromazine at $150 \mathrm{mg} / \mathrm{kg}$. On the basis of these results, it may be concluded that extracts of leaves have less anti-emetic potential and are comparable with that of Chlorpromazine (the reference drug).

T. Arumugam et al. reported significant antibacterial activity of $C$. asiatica extracted with methanol, acetone, chloroform, and water. The maximum inhibitory effect was found in methanol extract [33]. In another study, R. Perumal et al (2011) also noticed significant and higher rate of 
antimicrobial activity against various gram negative and gram positive bacteria [34]. However, in the present study, the methanolic crude extract didn't inhibit the growth of Staphylococcus aureus, Escherichia coli, Pseudomonas aeruginosa, Vibrio cholera and Entero bacter having zone size $4 \mathrm{~mm}, 1 \mathrm{~mm}, 2 \mathrm{~mm}, 5 \mathrm{~mm}$ and $3 \mathrm{~mm}$ respectively.

The IC50 value that is the concentration of drug required to inhibit the growth and proliferation of the cells by $50 \%$ was used an indicator in measuring the toxicity exhibited by the plant crude extracts [35]. By the standard set by National Cancer Institute, a crude extract is said to have anti-tumor properties when the IC50 value is less than $50 \mu \mathrm{g} / \mathrm{ml}$ [36]. In this study, the $\mathrm{IC}_{50}$ methanol extract was found to be $241.71 \mu \mathrm{g} / \mathrm{ml}$. However, Pittella et al. (2009) reported that the aqueous extract of $C$. asiatica does not show antiproliferative activity against mouse melanoma (B16F1), human breast cancer (MDA MB-231) and rat glioma (C6) cell lines with IC50 value of $698.0 \mu \mathrm{g} / \mathrm{mL}, 648.0 \mu \mathrm{g} / \mathrm{mL}$ and $1000.0 \mu \mathrm{g} / \mathrm{mL}$, respectively [36, 37]. In another study, purified fractions of $C$. asiatica showed anti-proliferative effect with IC50 values of $17 \mu \mathrm{g} / \mathrm{mL}$ and $22 \mu \mathrm{g} / \mathrm{mL}$ against Ehrlich ascites tumor cells [29, 38]. Mijanur et al. (2013) reported the IC50 values of $100 \% \& 50 \%$ ethanol extract and water extract of $C$. asiatica $35.6 \pm 1.3 \mu \mathrm{g} / \mathrm{ml}, 7.1 \pm 1.5$ $\mu \mathrm{g} / \mathrm{ml}$ and $10.3 \pm 1.2 \mu \mathrm{g} / \mathrm{ml}$ respectively [39]. Ascorbic acid was used as the positive control in this assay. Ascorbic acid, as adietary antioxidant, minimizes the damage caused by the reactive oxygen and nitrogen species [40]. The IC50 value of ascorbic acid was $27.23 \mu \mathrm{g} / \mathrm{ml}$ in this study.

The measurement of toxicity is very crucial in biological and ecological investigations. The $\mathrm{LC}_{50}$ methanol extract was found to be $39.06 \mu \mathrm{g} / \mathrm{ml}$. The positive control Vincristine sulfate showed $\mathrm{LC}_{50}$ at a concentration of $0.839 \mu \mathrm{g} / \mathrm{ml}$. From the results of the brine shrimp lethality bioassays, it can be well predicted that the methanol extract possesses cytotoxic properties. Rishikesh et al (2012) reported different mortality rates at different concentrations. The values found in the crude extract, n-hexane, and $\mathrm{CCl} 4$ were $1.905 \mu \mathrm{g} / \mathrm{ml}, 1.831$ $\mu \mathrm{g} / \mathrm{ml}$, and $1.152 \mu \mathrm{g} / \mathrm{ml}$ respectively. A significant LC50 value of the extract was noted $39.06 \mu \mathrm{g} / \mathrm{ml}$ [41] which demonstrates that the extract of $C$. asiatica shows the potentiality to kill cancer cells [42]. In this study, Comparison with positive control Vincristine signifies that cytotoxicity exhibited methanol extract might have mild antitumor and pesticidal activity. However, this cannot be confirmed without further higher and specific tests.

\section{Conclusion}

C. asiatica is used in vast range of pharmacological activity in addition to the food value. Pharmacological activity varies through the differences of extraction solvent. So, it should be paid a great emphasis. Various pharmacological activity such as antioxidant, antiemetic, cytotoxic, antimicrobial activity etc was demonstrated significant in this study.

\section{Acknowledgements}

The authors gratefully acknowledge the Manarat International University and State University of Bangladesh Research System for providing financial support to conduct this research work.

\section{References}

[1] M. E. Cartea, M. Francisco, P. Soengas, and P. Velasco, "Phenolic compounds in Brassica vegetables,"Molecules., 16(1), 251-280, 2011.

[2] S. J. Duthie, A. Ma, M. A. Ross, and A. R. Collins, "Antioxidant supplementation decreases oxidative DNA damage in human lymphocytes," Cancer Res., 56, 1291-1295, 1996.

[3] M. T. H Tanna, A. K Nath, M. N. Amin, M. Ibrahim, M. I. Chowdhury, M. E. H. Mukul, M. S. U. Rashed, A. Kabir, M. Ahmed, and M. S. Hossain, "Evaluation of antioxidants, membrane stabilizing, cytotoxic and anthelmintic activity with phytochemical screening of Chromolaena odorata: A medicinal shrub", Int J Pharm, 6(1):53-61, 2016.

[4] J. D. Mc Chesney, S. K. Venkataraman, and J. T. Henry, "Plant natural products: back to the future or into extinction?," Phytochemistry, 68(14), 2015-22, 2007.

[5] A.Z. Fake, R. D. Scalley, and A. G. Bailey, "Practical selection of antiemetics," Am Fam physician, 69, 1169-1174, 2004.

[6] A. I. Sajib, S. M. R. Dewan, A. Das, M. S. Sarwar, R. C. Sarkar, M. Ahmed, and M. S. Islam, "Invitro antimicrobial activity study and invivo antiemetic, antinociceptive activity evaluation of leaves extract of Erioglossum rubiginosum using experimental animal model," Oriental Pharmacy and Experimental Medicine, 15, 135-140, 2015.

[7] M. Balouiri, M. Sadiki, and S. K. Ibnsouda, "Methods for invitro evaluating antimicrobial activity: A review," Journal of Pharmaceutical Analysis, 6(2),71-79,2016.

[8] Nascimento, G. F. Gislene, J.Locatelli, P. C. Freitas, and G. L. Silva, "Antibacterial activity of plant extracts and phytochemicals on antibiotic-resistant bacteria," Braz. J. Microbiol. 31(4), 247-256, 2000.

[9] K.J. Davies, "Oxidative Stress: The Paradoxof Aerobic Life," Biochemical Society Symposium, 61, 1-31,1995.

[10] T. M. Mustafa, M. K. Sura, M. N. J. Abdul kadir, and I. A. Sarah, "Free radical and human health," International journal of innovation sciences and research, 4(6), 218-223, 2015.

[11] A. K. Tiwari, "Imbalance in antioxidant defense and human diseases: Multiple approach of natural antioxidant therapy," Curr.Sci., 81(9), 1179-1187, 2001.

[12] K. Bagchi, and S. Puri, "Freeradicals and antioxidants in health and disease," East. Mediterranean Health Jr., 4,350$360,1998$.

[13] P. Montuschi, J. P. Barnes, and J. L. Roberts, "Isoprostanes: markers and mediators of oxidative stress," The FASEB Journal, 18(15), 1791-1800, 2004. 
[14] N. Jose and K. K. Janardhanan, "Antioxidant and antitumor activity of Pleurotus florida,” Curr. Sci., 79, 941-943,2000.

[15] L. Stefanis, R. E. Burke, and L. A. Greene, "Apoptosis in neurodegenerative disorders," Curr Opin Neurol, 10, 299305, 1997.

[16] B. Halliwell, "How to characterize an antioxidant-Anupdate," Biochem Soc Symp, 61, 73-101, 1995.

[17] I. B. Suffredini, H. S. Sader, A. G. Gonçalves, A. O. Reis, A. C. Gales, A. D. Varella, and R. N. Younes, "Screening of antibacterial extracts from plants native to the brazilian amazonrain forest and atlantic forest," Braz. J. Med. Biol. Res., 37, 379-384, 2004.

[18] B. N. Ames, M. K. Shigenaga, and T. M. Hagen, "Oxidants, antioxidants, and the degenerative diseases of aging," Proc. Natl. Acad.Sci.,90,7915-7922,1993.

[19] K. J. Gohil, J. A. Patel, and A. K. Gajjar. "Pharmacological Review on Centella asiatica: A Potential Herbal Cure-all," Indian J Pharm Sci., 72(5), 546-56,2010.

[20] D. Arora, M. Kumar, and S. D. Dubey. "Centella asiatica-A review of its medicinal uses and pharmacological effects," Journal of Natural Remedies, 2(2), 143-149, 2002.

[21] L. Suguna, P. Sivakumar and G. Chandrakasan, "Effect of Centella Asiatica Extract on Dermal Wound Healing in Rats," Indian J. Exp. Biol., 34,1208-1211,1996.

[22] H. Rosen, A. Blumenthal, and J. McCallum, "Effect of asiaticoside on wound healing in rats," Experimental Medicine and Surgery, 125, 279-280,1967.

[23] K. Nalini, A. R. Aroor, K. S. Karanth and A. Rao, "Effect of Centella Asiatica Fresh Leaf Aqueous Extracton Learning Memory and Biogenic Amine Turnover in Albino Rats," Fitoterapia, 63, 232-237, 1992.

[24] A.Yoshinori, M. Reiko, and T. Tsumematsu, "Mono and sesquiterpenoids from hydrocotyle and Centella species," Phytochemistry, 21, 2590-2592, 1982.

[25] S.C. CH, M. Haritha, B. S. Rao, V. Sharanand, V. Meena, "Pharmacognostic and Pharmacological Aspects of Centella Asiatica,” Int. J. Chem. Sci., 9(2), 784-794, 2011.

[26] F. X. Maquart, G. Bellon, P. Gillery, Y. Wegrowski, and J. P. Borel, "Stimulation of collagen synthesis in fibroblast cultures by a triterpene extracted from Centella asiatica," Connective Tissue Research, 24, 107-120, 1990.

[27] Y. Akita, Y. Yang, T. Kawai, K. Kinoshita, K. Koyama, and K. Takahashi, "New assay method for survey in antiemetic compounds from natural sources," Nat Prod Sci., 4, 72-77, 1998.

[28] N. Sreejayan, and M. N. A. Rao, "Freeradical scavenging activity of curcuminoids,” Drug Res., 46, 169-171, 1997.

[29] F. Pittella, R. C. Dutra, D. D. Junior, M. T. P. Lopes and N. R. Barbosa, "Antioxidant and Cytotoxic Activities of Centella asiatica (L) Urb.," Int J Mol Sci., 10(9), 3713-3721, 2009.
[30] J. Harwig, and P. M. Scott, "Brineshrimp (Artemia salina L.) larvaesa screening system for fungal toxins," Appl Microbiol, 21(6), 1011-6,1971.

[31] B. N. Meyer, N. R. Ferrigni, J. E. Putnam, J. E. Jacobsen, D. E. Nichols, and J. L. McLaughlin, "Brineshrimp: A convenient general bioassay for active plants constituents," J Med Plant Res., 45, 31-34, 1982.

[32] S. Hossain, G. Kader, F. Nikkon, and T. Yeasmin, "Cytotoxicity of the rhizomes of medicinal plants," Asian Pac J Trop Biomed, 2(2), 125-127, 2012.

[33] T. Arumugam, M. Ayyanar, Y. J. Koil Pillai, and T. Sekar, "Phytochemical screening and antibacterial activity of leaf and callus extracts of Centella asiatica," Bangladesh Journal of Pharmacology, 6(1), 55-60, 2011.

[34] R. P. Samy, and I. V. T. K. Chow, "Antimicrobial and Phytochemical Analysis of Centella asiatica (L.)," Nature Precedings, 11(37), 1-6, 2011.

[35] M. D. Fellows and M. R. O’Donovan,"Cytotoxicity in cultured mammalian cells is a function of the method used to estimate it.," Mutagenesis,22(4), 275-280, 2007.

[36] M. R. A. Mans, A. B. D. Rocha and G. Schwartsmann, "Anticancer drug discovery and development in Brazil: Targeted plant collection as rational strategy to acquire candid ateanticancerc ompounds," The Oncologist, 5, 185-198, 2000.

[37] M.N. Amin, S. Banik, M. Ibrahim, M. M. R. Moghal, M. S. Majumder, R. Siddika, M. K. Alam, K. M. R. M. Jitu, S. N. Anonna. "A Study on Ardisia solanacea for Evaluation of Phytochemical and Pharmacological Properties," International Journal of Pharmacognosy and Phytochemical Research, 7(1), 8-15, 2015.

[38] M. S. Majumder, M. N. Amin, M. M. R. Moghal, S. Banik, A. Kar, and M. M. Hossain. "Anthelmintic and Cytotoxic Activities of Two Medicinal Plants: Polygonum viscosum and Aphanamixis polystachya Growing in Bangladesh," J. Sci. Res., 6(2), 339-345,2014.

[39] T. D. Babu, G. Kuttan and J. Padikkala, "Cytotoxic and antitumor properties of certain taxa of Umbelliferae with special references to Centella asiatica (L.) Urban," Journal of Ethnopharmacology, 48(1), 53-57, 1995.

[40] M. Rahman, S. Hossain, A. Rahaman, N. Fatima, T. Nahar, B. Uddin and M.A. Basunia, "Antioxidant Activity of Centella asiatica (Linn.) Urban: Impact of Extracti on Solvent Polarity," Journal of Pharmacognosy and Phytochemistry, 1(6), 27-32, 2013.

[41] Rishikesh, D. R. Ghosh, M. A. Islam, S. M. S. Islam, M. M. Rahman, "Brine Shrimp Lethality Bioassay Of Methanolic Extract Of Centella asiatica Leaves," Int. Res J Pharm. App Sci., 2(5), 39-44, 2012.

[42] K. M. R. M. Jitu, D. Debnath, S. Asad, R. C. Das, and A. Sultana. "Phytochemical screening and evaluation of cytotoxic activity of Pandanus fascicularis L.(Fruits)," Discovery Phytomedicine, 4(3), 1-4, 2017. 